\title{
Çan Linyitinin Sorgum Biyokütlesi İle Gazlaştırılmasında Biyokütle Oranı ve Sıcaklığın Etkisi
}

\author{
Açelya SEÇER* (D) \\ "Çukurova Üniversitesi Fen Edebiyat Fakültesi, Kimya Bölümü, 01130, Adana, Türkiye
}

Geliş / Received: 26.02.2019, Kabul / Accepted: 09.10.2019

\section{$\ddot{O} z$}

Çan linyiti ve sorgum biyokütlesi farklı oranlarda sorgum içerecek şekilde karıştırılarak, $700^{\circ} \mathrm{C}$ sıcaklıkta birlikte gazlaştırılmış ve karışımdaki sorgum oranının toplam gaz hacmi ile gaz ürün dağılımına etkileri incelenmiştir. Hem toplam gaz hacmi hem de üretilen hidrojen gazının miktarı açısından en etkin sorgum konsantrasyonu \% 25 olarak belirlenmiştir. \%25 sorgum içeren kömür/sorgum karışımı, 700, 800 ve $900{ }^{\circ} \mathrm{C}$ sıcaklıklarda gazlaştırılarak, sıcaklık artışının toplam gaz hacmi ve gaz ürün dağılımındaki etkileri incelenmiştir. En etkin gazlaştırma sıcaklığ $900{ }^{\circ} \mathrm{C}$ olarak belirlenmiştir. \%25 sorgum içeren 1 gram kömür/sorgum karışımının $900{ }^{\circ} \mathrm{C}$ sıcaklıkta birlikte gazlaştırılmasından \% 71,4 hidrojen gazı içeren $2729 \mathrm{~mL}$ gaz elde edilmiştir.

Anahtar Kelimeler: kömür, biyokütle, birlikte gazlaştırma, hidrojen

The Effects of Biomass Ratio and Temperature on Co-Gasification of Çan Lignite with Sorghum Biomass

\begin{abstract}
Co-gasification experiments of mixtures of Çan lignite and sorghum biomass containing different concentrations of sorghum were performed and the effects of biomass ratio in coal/biomass mixtures on total gas volumes and syngas product distributions were evaluated. The most effective sorghum concentration was determined as $25 \%$, in terms of both total gas volumes and hydrogen gas production volumes. he coal / sorghum mixture containing $25 \%$ sorghum was gasified at temperatures of 700,800 and $900{ }^{\circ} \mathrm{C}$ and the effects of temperature increase on total gas volume and gas product distribution were investigated. The most effective gasification temperature was determined as $900^{\circ}$ C. $2729 \mathrm{~mL}$ of gas with $71.4 \%$ hydrogen gas was obtained by co-gasification of 1 gram of coal / sorghum mixture containing $25 \%$ sorghum at $900{ }^{\circ} \mathrm{C}$.
\end{abstract}

Keywords: : coal, biomass, co-gasification, hydrogen

\section{Giriş}

Dünya enerji ihtiyacının halen büyük bir çoğunluğunu karşılamakta olan fosil yakıtlar arasında kömür, var olan rezervleri ve üretim maliyetleri açısından değerlendirildiğinde kullanımına devam edilmesi zorunlu olan başlica

fosil

yakitlardandir (www.worldenergy.org). Geleneksel kömür kullanımının çevresel etkileri nedeniyle, çevreye daha az zarar veren alternatif kömür kullanım prosesleri geliştirilmektedir. Gazlaştırma, kömürün su buharı, hava ve/veya su/oksijen, karbondioksit ya da 
bunların karışımını içeren gazlaştırıcı elemanlarla yüksek sıcaklıklarda reaksiyona sokularak, $\mathrm{H} 2, \mathrm{CO}, \mathrm{CO} 2$ ve $\mathrm{CH} 4$ gazların içeren sentez gazının üretildiği bir yöntemdir (Minchener, 2005). Ayrica bu şekilde üretilen gaz karışımı içerisindeki CO2 oranı yanma prosesine göre daha az olmakta ve kömürde yer alan mevcut kükürt, $\mathrm{SO} 2$ yerine daha kolay giderilebilen H2S'e dönüştürülmektedir. $\mathrm{Bu}$ yöntem su buharı varlığında, su-gaz değişim reaksiyonu aracılığıyla, yüksek oranda hidrojen içeren sentez gazı üretimi için kullanılabilmektedir (Moore ve Pearce, 2006). Kömür gazlaştırma yolu ile hidrojen üretimi, kömürün yeni nesil enerji kayaklarına entegrasyonu açısından önemli bir yöntemdir (Stiegel ve Ramezan, 2006). Kömürden gazlaştırma yol ile hidrojen üretimini arttırmak için, su-gaz değişim reaksiyonunda yüksek katalitik etkinlik gösteren alkali, toprak alkali metallerin oksitleri ve bu metallerin çeşitli tuzları katalizör olarak kullanılmaktadır (Veraa ve Bell,1978). Biyokütle, yapısında doğal olarak bu alkali ve toprak alkali metallerin bulundurmaktadır (Howaniec ve Smolinski, 2013). Yapılan çalışmalar, kömürün tek başına gazlaştırılması yerine biyokütle ile karıştırılarak birlikte gazlaştırılmasının, biyokütlenin yapısında yer alan inorganik tuzların su-gaz değişim reaksiyonunda gösterdiği katalitik etkiler sayesinde hidrojen gazı üretim verimini arttırabileceğini göstermiştir (Howaniec vd., 2011). Ayrıca biyokütlenin CO2 nötr doğası, gazlaştırma prosesi sonucu atmosfere salınan net $\mathrm{CO} 2$ miktarının azalmasını sağlar. Birlikte gazlaştırma prosesinin enerji performansı, sıcaklık, gazlaştırıcı ajan akış hızı, reaktör tipi, biyokütle türü, kömür türü, kömür/biyokütle karışım oranı gibi çeşitli parametrelerden etkilenmektedir. Literatürde bu parametrelerin etkilerini inceleyen çeşitli çalışmalar mevcuttur (Howaniec ve
Smolinski, 2013; Howaniec ve Smolinski, 2014; Rizkiana vd., 2014; Velez vd., 2009; Jeong vd., 2015; Pinto vd. 2003; Kumabe vd., 2007; Lapuerta vd., 2008; Brar vd., 2012). Dünya toplam linyit/alt bitümlü kömür rezervlerinin yaklaşı $\% \quad 3,2$ si Türkiye'de bulunmaktadır. Ancak bu linyitlerin büyük bir kısmının 1sıl değeri düşük olduğundan termik santrallerde kullanımı ön plana çıkmaktadır (www.enerji.gov.tr). Çan linyiti kül ve kükürt içeriği yüksek olan ve kalorifik değeri düşük (3000 kcal/kg) olan bir linyittir. Sahadaki 87 milyon ton olan toplam görünür rezervin yaklaşık 74 milyon tonu işletilebilir rezervdir (Şengüler, 2014). Bu linyitlerin birlikte gazlaştırma yolu ile hidrojen üretiminde kullanılması çevreci ve etkin bir şekilde kullanılmaları açısından iyi bir alternatif olabilir. Çalışmada biyokütle kaynağı olarak sorgum, şeker içeriğinin oldukça yüksek olmasının yanı sıra, her iklim koşuluna kolaylikla adapte olabilmesi, pestisit ve gübreleme ihtiyacının diğer bitkilere göre daha az olması gibi sebeplerle üretimi kolay bir enerji bitkisi olması ve ayrıca ülkemiz iklim koşullarında rahatlıkla yetiştirilebilmesi nedenleri ile seçilmiştir. (Hasanoğlu vd., 2014). Bu çalışmada sorgum biyokütlesi ve Çan linyiti, su buharı varlığında birlikte gazlaştırılarak, karışımdaki sorgum oranının ve operasyon sicaklığının toplam gaz hacimleri ve gaz ürün dağılımlarındaki etkileri incelenmiştir. Türkiye'de rezervi oldukça yüksek olan Çan linyitinin ve sorgum biyokütlesinin birlikte gazlaştırılması ile ilgili herhangi bir çalışma gerçekleştirilmemiştir. $\mathrm{Bu}$ çalışma, Çan linyiti ve benzeri Türkiye linyitlerin biyokütle ile birlikte gazlaştırılmasının sentez gazı ve özellikle de yüksek verimde hidrojen üretimi için daha çevreci bir yaklaşımla kullanılabileceği konusunda bir ön çalışma niteliğindedir. 


\section{Materyal ve Metot}

Çalışmada Çan linyiti ve sorgum biyokütlesi kullanılmıştır. Çan linyiti ve sorgum biyokütlesine ait kısa analiz sonuçları Tablo 1'de verilmiştir. Çan linyiti ve sorgum öğ̈̈ülerek sırasıyla 60 ve 140 mesh elekten geçecek şekilde boyutlandırılmıştır. Kömür ve biyokütle örneklerine herhangi bir ön işlem uygulanmamıştır.

Tablo 1. Çan linyiti ve sorgum biyokütlesinin kısa analiz değerleri.

\begin{tabular}{|c|c|c|c|}
\hline \multirow[t]{2}{*}{ Analizler } & \multicolumn{2}{|c|}{ Analiz Sonuçları } & \multirow[t]{2}{*}{ Yöntem } \\
\hline & Çan & Sorgum & \\
\hline $\mathrm{C}(\mathrm{ag} \%, \mathrm{~kb})^{*}$ & 56,32 & 39,8 & ASTM D 5373-16 \\
\hline $\mathrm{H}(\mathrm{ag} \%, \mathrm{~kb})$ & 3,84 & 0,8 & ASTM D 5373-16 \\
\hline $\mathrm{N}(\mathrm{ağ} \%, \mathrm{~kb})$ & 1,01 & 5,2 & ASTM D 5373-16 \\
\hline $\mathrm{S}(\mathrm{ağ} \%, \mathrm{~kb})$ & 5,61 & - & ASTM D 4239-14e2 \\
\hline $\mathrm{O}(\mathrm{ağ} \%, \mathrm{~kb})$ & 10,13 & 54,2 & ASTM D 3176-16 \\
\hline Nem (ăg \%) & 6,14 & 8,1 & ASTM D 7582-15 \\
\hline Kül (ağ \%, kb) & 23,09 & 8,4 & ASTM D 7582-15 \\
\hline Üst Is1l Değer (cal/g, kb) & 5141 & - & ASTM D 5865-13 \\
\hline Alt Isıl Değer (cal/g, kb) & 4942 & - & ASTM D 5865-13 \\
\hline & & & ISO 1928-09 \\
\hline
\end{tabular}

\section{*kuru bazda}

Gazlaştırma deneyleri sabit yataklı paslanmaz çelik reaktörde (iç çap 0,56", diş çap 1,4") gerçekleştirilmiştir. Kömür ve biyokütle (toplamda kuru külsüz bazda (kkb) $1,0 \mathrm{~g})$ $\% 0, \% 20, \% 25, \% 33, \% 66, \% 75, \% 100$ biyokütle oranları içerecek şekilde karıştırılarak reaktör içine yerleştirilmiştir. Reaktör, yüksek sıcaklık fırını içerisinde dakikada $30{ }^{\circ} \mathrm{C}^{\prime}$ lik artışlarla istenilen sıcaklığa kadar 1sıtılmıştır. Gazlaştırıcı ajan olan su bir HPLC pompası ile $0,5 \mathrm{~mL} \mathrm{dk}^{-1}$ akış hızında reaktöre gönderilmiştir. Reaktörden çıkan su gaz karışımı geri soğutucudan geçirilerek gaz-sıvı ayırıcı rezervuara giriş yapmıştır. $\mathrm{Bu}$ ayırıcıdan çıkan gaz karışımı kadmiyum asetat çözeltisinden geçirilmiş ve $\mathrm{H}_{2} \mathrm{~S}$ gazı $\mathrm{CdS}$ çeklinde çöktürülerek gaz karışımından ayrılmıştır. H2S den ayrılan gaz karışımı bir gaz toplama büretinde toplanarak hacmi belirlenmiştir. Toplanan gazın nitel ve nicel analizleri iki kanallı termal elektrik iletkenlik (TCD) detektörlü Varian-450 gaz kromatografi cihazı ile yapılmıştır. Gaz analizleri ile ayrıntılı bilgiler önceki çalışmalarda verilmektedir (Seçer vd., 2018). Gaz-sıv1 ayırıc1 rezervuarda 
toplanan sıvılar diklorometan çözücüsü ile ekstrakte edilmiş ve Thermo TR-5MS kapiler kolonlu $(60 \mathrm{~m} \times 0.25 \mathrm{~mm}$ ID $\times 0.25$ $\mu \mathrm{m})$, Thermo Finnigan GC-MS gaz kromatografisi-kütle spektrometresi cihazında analizleri gerçekleştirilmiştir.

\section{Bulgular}

Sorgum ve Çan kömürü, $0,5 \mathrm{~mL} \mathrm{dk}-1 \mathrm{su}$ akış hızında, $700 \square \mathrm{C}$ sıcaklıkta, farklı oranlarda sorgum içerecek şekilde karıştırılarak birlikte gazlaştırılmıştır. Farklı biyokütle oranlarının birlikte gazlaştırmada etkisi, toplam gaz hacimleri, sentez gazı içindeki ürün dağılımları ve gazlaştırma sonrası toplanan sıvıların ürün içerikleri açısından değerlendirilmiştir. Sonuçlar Tablo 1 ve Şekil 1' de özetlenmektedir.

Tablo 1. Farklı oranlarda sorgum içeren kömür/sorgum karışımlarının $0,5 \mathrm{~mL} \mathrm{dk}{ }^{-1}$ su akış hızı, $700{ }^{\circ} \mathrm{C}$ sıcaklıkta gazlaştırılmalarından elde edilen toplam gaz hacimleri ve gazların bileşimleri.

\begin{tabular}{llllll}
\hline \multirow{2}{*}{ \% Sorgum } & $\begin{array}{l}\text { Toplam } \\
\text { gaz } \\
(\mathrm{mL})\end{array}$ & \multicolumn{5}{l}{ Gaz kompozisyonu (\%) } \\
\cline { 3 - 6 } 0 & $\mathrm{H}_{2}$ & $\mathrm{CO}$ & $\mathrm{CH}_{4}$ & $\mathrm{CO}_{2}$ \\
20 & $1251 \pm 20$ & $66,5 \pm 0,6$ & $16,3 \pm 0,2$ & $4,6 \pm 0,1$ & $13,6 \pm 0,3$ \\
25 & $1252 \pm 16$ & $68,4 \pm 0,1$ & $12,6 \pm 0,2$ & $4,6 \pm 0,1$ & $14,4 \pm 0,1$ \\
33 & $1331 \pm 12$ & $69,8 \pm 0,1$ & $10,8 \pm 0,1$ & $4,2 \pm 0,1$ & $15,2 \pm 0,1$ \\
50 & $1159 \pm 23$ & $69,2 \pm 0,2$ & $11,2 \pm 0,1$ & $4,5 \pm 0,1$ & $15,1 \pm 0,2$ \\
66 & $1135 \pm 18$ & $69,3 \pm 0,2$ & $11,4 \pm 0,3$ & $4,5 \pm 0,1$ & $14,8 \pm 0,2$ \\
75 & $1020 \pm 8$ & $69,2 \pm 0,1$ & $11,9 \pm 0,1$ & $4,0 \pm 0,1$ & $14,9 \pm 0,1$ \\
100 & $1022 \pm 14$ & $69,5 \pm 0,3$ & $12,2 \pm 0,1$ & $3,5 \pm 0,1$ & $14,8 \pm 0,2$ \\
& $964 \pm 6$ & $70,1 \pm 0,6$ & $11,1 \pm 0,1$ & $3,1 \pm 0,1$ & $15,7 \pm 0,3$ \\
\hline
\end{tabular}




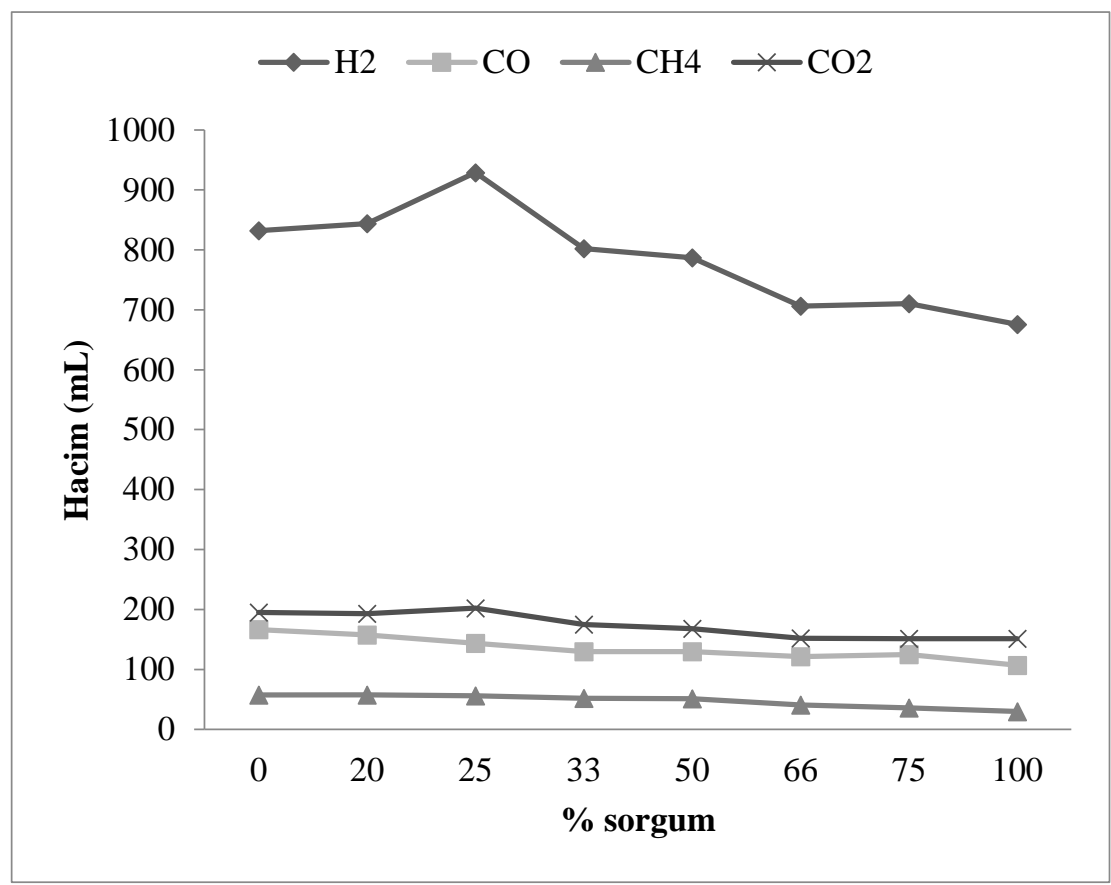

Şekil 1. Farklı oranlarda sorgum içeren kömür/sorgum karışımlarının 0,5 mL dk ${ }^{-1}$ su akış hızı, $700{ }^{\circ} \mathrm{C}$ sıcaklıkta gazlaştırılmalarından elde edilen gaz karışımı içindeki hacimlerinin \% sorgum oranına göre değişimleri.

Sonuçlar gazlaşan karışımın biyokütle konsantrasyonunun hem üretilen toplam gaz hacimlerini hem de ürün gazların karışımdaki oranlarını etkilediğini göstermektedir. En yüksek gaz hacmi, \%25 biyokütle içeren karışımın gazlaştırılmasından elde edilmiştir. Biyokütlenin uçucu bileşen içeriği kömürünkinden fazladır ve reaktivitesi yüksektir. Gazlaşan maddedeki uçucu bileşenler hızla serbest radikallere dönüşerek ayrışma, oksidasyon ve gazlaşma reaksiyonlarının hızlarını arttırır. $\mathrm{Bu}$ nedenle kömür/biyokütle karışımındaki biyokütle oranının artışı, karbon dönüşüm reaksiyonlarının artmasına ve daha fazla gaz ürün oluşumuna neden olmaktadır. Bununla birlikte, bu etki karışımdaki biyokütle oranı en fazla $\% 25$ oluncaya dek geçerlidir bu bileşimin üzerindeki konsantrasyonlarda toplam gaz miktarının azaldığ1 gözlemlenmiştir (Tablo 1). $\mathrm{Bu}$ durum biyokütlenin kömüre kıyasla daha düşük miktarda sabit karbon içermesine bağlanmıştır. Karışımın biyokütle içeriği arttıkça gazlaşan karışımdaki toplam sabit karbon miktarı azalmakta ve dolayısı ile gazlaşan karbon miktarı azalmaktadır. $\mathrm{Bu}$ nedenle, \% 25 in üzerindeki biyokütle konsantrasyonlarında karbon dönüşümlerinin azalması ile birlikte toplam gaz verimleri de düşmüştür. Diğer taraftan, karışımının biyokütle oranındaki artış gaz karışımının $\% \mathrm{H}_{2}$ oranın artmasına neden olduğunu gözlemlenmiştir (Tablo 1). Birlikte gazlaştırmanın avantajı, biyokütlenin içeriğinde bulunan özellikle alkali ve toprak alkali metallerin oksitlerini içeren inorganik materyallerin hidrojen gazı oluşumunda rol alan su-gaz değişim reaksiyonunda (1) katalizör etkisi göstermesinden ileri gelmektedir.

$\mathrm{CO}+\mathrm{H}_{2} \mathrm{O} \rightleftharpoons \mathrm{CO}_{2}+\mathrm{H}_{2}$

En yüksek hidrojen gazı hacmi de $\% 25$ biyokütle içeren karışımın gazlaştırılmasından elde edilmiştir (Şekil 1). $\mathrm{Bu}$ değerin üzerindeki 
konsantrasyonlarda ürün gazının $\%$ hidrojen içeriğinin nispeten arttı̆̆ gözlemlense de, yüksek biyokütle konsantrasyonlarında toplam gaz hacminde meydana gelen azalma, oluşan hidrojen gazının da hacimsel olarak azalmasına neden olmuştur. Biyokütle oranının artışıyla birlikte hem gaz karışımındaki \%CO oranı hem de toplam gaz içindeki $\mathrm{CO}$ hacmi azalmaktadir. Bu durum, su-gaz değişim reaksiyonunun katalizörlerin etkisiyle hizlanması sonucunda CO tüketiminin artmasına bağlanabilir. Ayrıca gazlaşan karbon miktarının azalması da CO oluşumunun azalmasına neden olmaktadır. $\mathrm{CO}_{2}$ oluşumunun karışımın biyokütle oranının artışı ile birlikte artması da su-gaz değişim reaksiyonunun hızlanmasına bağlanmıştır. Biyokütle miktarının karışımdaki $\mathrm{CH}_{4}$ gazının oranı üzerine belirgin bir etkisi olmamakla birlikte toplam gaz oluşumunun azalması, biyokütle oranı arttıkça oluşan $\mathrm{CH}_{4}$ gazının miktarının azalmasına neden olmuştur. Kömür/biyokütle karışımındaki bileşenlerin karışımdaki miktarlarının tek başlarına gazlaştırılmalarından edilen toplam gaz hacimleri ve gazların bileşimleri Tablo 2'de verilmiştir. $\mathrm{Bu}$ sonuçlar birlikte gazlaştırma deneyi sonuçları ile de karşılaştırılmıştır.

Tablo 2. Sorgum biyokütlesi ve Çan kömürünün $0,5 \mathrm{~mL} \mathrm{dk}{ }^{-1}$ su akış hızı ve $700{ }^{\circ} \mathrm{C}$ sıcaklıkta tek başlarına gazlaştırılmalarından elde edilen sonuçların birlikte gazlaştırma sonuçları ile karşılaştırılması.

\begin{tabular}{llllll}
\hline \multicolumn{5}{c}{ Toplam Gaz (mL) } & \multicolumn{4}{l}{ Gaz kompozisyonu (\%) } \\
\cline { 3 - 6 } & & $\mathrm{H}_{2}$ & $\mathrm{CO}$ & $\mathrm{CH}_{4}$ & $\mathrm{CO}_{2}$ \\
$\mathrm{~S}^{*}$ & $247 \pm 10$ & $70,1 \pm 0,2$ & $11,3 \pm 0,9$ & $3,1 \pm 0,4$ & $15,7 \pm 0,2$ \\
$\mathrm{~K}^{* *}$ & $953 \pm 26$ & $66,5 \pm 0,3$ & $14,0 \pm 0,2$ & $4,4 \pm 0,8$ & $15,1 \pm 1,0$ \\
$\mathrm{~S} / \mathrm{K}$ & $1331 \pm 12$ & $69,8 \pm 0,1$ & $10,8 \pm 0,1$ & $4,2 \pm 0,1$ & $15,2 \pm 0,1$
\end{tabular}

*Sorgum;**Çan linyiti

Sorgumun karışımda yer alan oranı tek başına gazlaştırıldığında $247 \mathrm{~mL}$ gaz elde edilirken kömürün karışımdaki miktarı tek başına gazlaştırıldığında elde edilen gazın hacmi $953 \mathrm{~mL}$ dir. Bu bileşenlerin birlikte gazlaştırılmasından elde edilen gaz hacminin (1331 $\mathrm{mL})$, bu sicaklikta bileşenlerin tek başlarına gazlaştırılmalarından elde edilen gaz hacimleri toplamından (1200 mL) fazla olduğu gözlemlenmiştir. Birlikte gazlaştırma sonucu gaz karışımındaki $\mathrm{H}_{2}$ oranı kömürün tek başına gazlaștırılmasından yaklaşık \%3 daha fazladır. Toplam gaz hacmindeki artış da dikkate alındığında, birlikte gazlaştırma sonucu üretilen $\mathrm{H}_{2}$ gazı miktarının da arttığ1 gözlemlenmiştir. Bu sonuç birlikte gazlaştırmanın hem toplam gaz verimi hem de hidrojen verimini arttıran sinerjik etkilerini kanıtlamaktadır.

Sorgum ve kömürün tek başlarına gazlaştırılmaları sonrası ve \%25 sorgum içeren kömür/sorgum karışımının birlikte gazlaştırılması sonrasında, sıvıların GC/MS analizlerine ait sonuçlar Şekil 2 ve 
Tablo 3 de verilmektedir. Sorgumun tek başına gazlaştırılmasından sonra oluşan sıvının fenol türevi bileşenlerin miktarları açısından kömüre nazaran daha zengin olduğu gözlemlenmektedir. Lignoselülozik biyokütlenin üç ana bileşeninden biri olan lignin, 1sıtıldığında lignin komponentleri, monomerik ve oligomerik fenolik

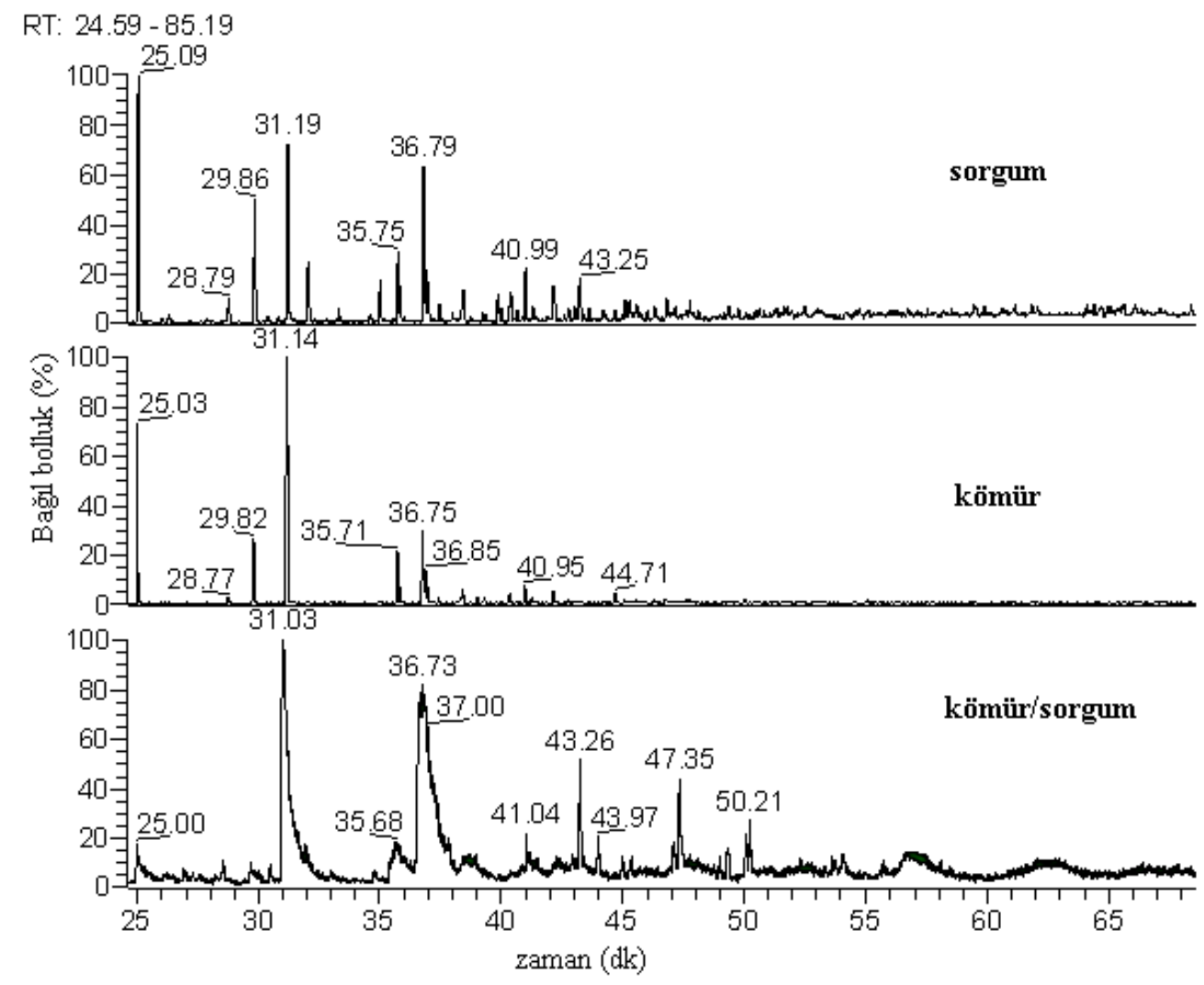

Şekil 2. Sorgum ve Çan kömürünün $0,5 \mathrm{~mL} \mathrm{dk}^{-1}$ su akış hızı ve $70{ }^{\circ} \mathrm{C}$ sıcaklıkta tek başlarına gazlaştırılmaları sonrası sıvıların GC/MS analizi sonuçlarının birlikte gazlaştırma sonrası sıvıların GC/MS analizi sonuçları ile karşılaştırılması.

Tablo 3. Gazlaştırma sonrası sıvıların GC/MS analizleri sonucu tespit edilen ürünler.

\begin{tabular}{|c|c|c|c|}
\hline $\begin{array}{l}\text { Alıkonma } \\
\text { süresi (dk) }\end{array}$ & Ürün & $\begin{array}{l}\text { Alıkonma } \\
\text { süresi (dk) }\end{array}$ & Ürün \\
\hline 25,0 & fenol & 36,7 & 4-etil-fenol \\
\hline 28,7 & 2,3-Dimetil-2-siklopenten-1-on & 40,9 & m-krezol,4-etil- \\
\hline 29,8 & $\mathrm{~m}$-krezol & 43,2 & 4-etil-2-metoksi-fenol \\
\hline 31,1 & $\mathrm{p}$-krezol & 47,3 & 2,6-dimetoksi fenol \\
\hline 35,7 & 2,5-ksilenol & 50,2 & 7-metil-1-indanon \\
\hline
\end{tabular}

bileşenleri oluşturmak üzere depolimerize olmaktadır ve aynı sicaklıkta yapılan gazlaştırma sonrası çözeltilerde, sorgum kullanılan deneylerde fenol türevi bileşenlerin, sinyal şiddetleri karşılaştırıldığında miktarlarının ve çeşitliliğinin arttı̆̆ gözlemlenmektedir. 
Sicaklığın birlikte gazlaştırma üzerindeki etkisi

Sıcaklığın birlikte gazlaştırmaya etkisinin incelenmesi amaciyla \%25 sorgum içeren kömür/sorgum karışımı 700, 800 ve 900

${ }^{\circ} \mathrm{C}$ sıcaklıklarda gazlaştırılmış ve elde edilen toplam gaz hacimleri ile gazların bileşimi incelenmiştir. Sonuçlar Şekil 3'de verilmektedir.

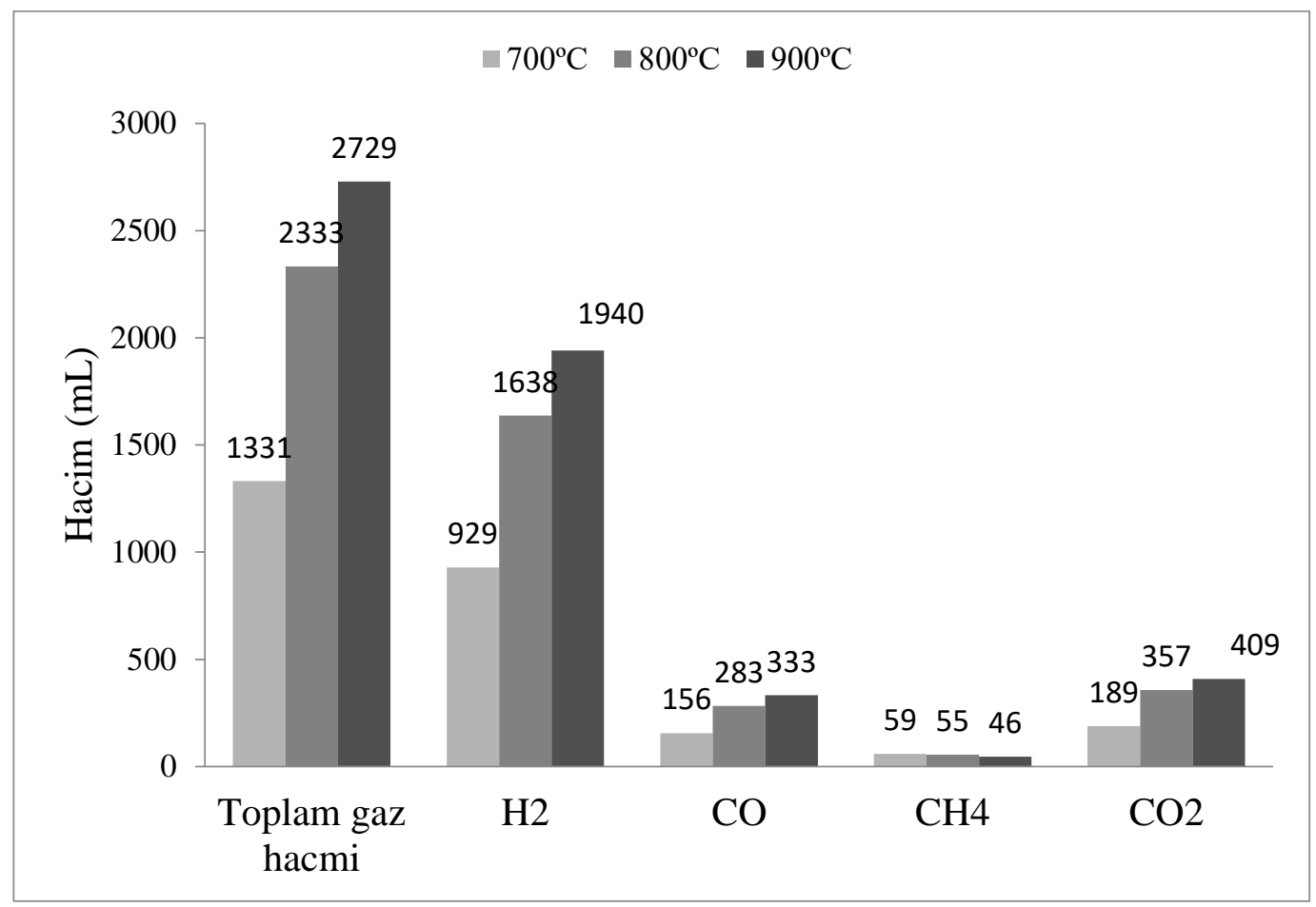

Şekil 3. \%25 sorgum içeren kömür/sorgum karışımlarının $0,5 \mathrm{~mL} \mathrm{dk}^{-1}$ akış hızı, $900{ }^{\circ} \mathrm{C}$ sıcaklıkta gazlaştırılmalarından elde edilen gaz ürün dağılımları.

Sıcaklık artı̧̧ çoğunluğu endotermik olan kömür gazlaşma reaksiyonlarının hızlanmasına ve karbon dönüşümlerinin artmasına neden olmaktadır. Bu nedenle gazlaşma sıcaklığının $700^{\circ} \mathrm{C}$ den $900^{\circ}$ $C^{\prime} y e$ artışı ile birlikte toplam gaz hacminde beklendiği üzere belirgin bir artış bir artış gözlemlenmiş̧ir. En yüksek toplam gaz hacmi $(2729 \mathrm{~mL})$ ve hidrojen gazı hacmine $(1940 \mathrm{~mL}) 900{ }^{\circ} \mathrm{C}$ de ulaşılmıştır. $900{ }^{\circ} \mathrm{C}$ birlikte gazlaştırma için hem toplam gaz hacmi hem de üretilen $\mathrm{H}_{2}$ gazı açısından en iyi koşulların sağlandığı sıcaklıktır. Hidrojen üretiminde etkin olan su gaz değişim reaksiyonunun en etkin olduğu sıcaklık aralığ $1850-900{ }^{\circ} \mathrm{C}$ dir. Bu nedenle karışımdaki hidrojen gazı oranının sıcaklığın $900{ }^{\circ} \mathrm{C}$ ye çıkarılması ile birlikte yaklaşık \%3 arttığ gözlemlenmiştir. $\mathrm{CH}_{4}$ reformlama reaksiyonunun endotermik doğası gereği sıcaklık artışı ile birlikte $\mathrm{CH}_{4}$ ün $\mathrm{H}_{2}$ ve $\mathrm{CO}_{2}$ ye dönüşümünün artmasıyla birlikte ürün gazı içeriğindeki $\mathrm{CH}_{4}$ miktarında azalma gözlemlenmiştir. Üretilen hidrojen gazının miktarındaki

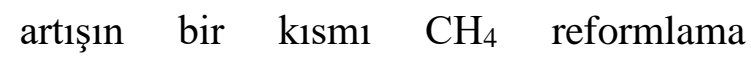
reaksiyonunun hızının sıcaklık artışı ile birlikte artmış olmasına bağlanabilir. Aynı şekilde sıcaklık artışı ile birlikte, hem sugaz değişim reaksiyonu hem de $\mathrm{CH}_{4}$ reformlama reaksiyonlarının hızlarının artışına bağlı olarak, ürün gazı içreğindeki $\mathrm{CO}_{2}$ miktarında da artış gözlemlenmiştir. Sıcaklık değişimi ile birlikte gaz karışımı içindeki \%CO oranları arasında önemli bir fark gözlemlenmezken, toplam gaz 
hacmindeki artışla birlikte $900{ }^{\circ} \mathrm{C}$ de üretilen $\mathrm{CO}$ hacminin de $\operatorname{artt1ğ} 1$ gözlemlenmiştir. Tablo 3'te kömür/biyokütle karışımındaki bileşenlerin miktarlarının $900^{\circ} \mathrm{C}$ de tek başlarına

Tablo 3. Sorgum ve Çan kömürünün $0,5 \mathrm{~mL} \mathrm{dk}^{-1}$ su akış hızı ve $700{ }^{\circ} \mathrm{C}$ sıcaklıkta tek başlarına gazlaştırılmalarından elde edilen sonuçların birlikte gazlaştırma sonuçları ile karşılaştırılması.

\begin{tabular}{llllll}
\hline & $\begin{array}{l}\text { Toplam } \\
\text { gaz }(\mathrm{mL})\end{array}$ & $\mathrm{H}_{2}(\%)$ & $\mathrm{CO}_{2}(\%)$ & $\mathrm{CO}(\%)$ & $\mathrm{CH}_{4}(\%)$ \\
\hline $\mathrm{K}$ & $2324 \pm 42$ & $67,1 \pm 0,4$ & $17,5 \pm 0,4$ & $12,5 \pm 0,2$ & $2,9 \pm 0,3$ \\
$\mathrm{~S}$ & $360 \pm 10$ & $71,1 \pm 0,7$ & $16,0 \pm 0,9$ & $2,8 \pm 0,1$ & $9,8 \pm 0,8$ \\
$\mathrm{~K} / \mathrm{S}$ & $2729 \pm 98$ & $71,4 \pm 0,1$ & $15,0 \pm 1,0$ & $12,2 \pm 0,8$ & $1,7 \pm 0,4$ \\
\hline
\end{tabular}

Sorgum ve Çan kömürünün, birlikte gazlaştırmada kullanılan karışım içerisindeki miktarlarının tek başlarına gazlaştırılmaları sonucu elde edilen gaz hacimlerinin matematiksel toplamı 2009 $\mathrm{mL}$ iken, birlikte gazlaştıııldığında, aynı koşullarda elde edilen gaz hacmi 2729,0 ml olmuştur. Hidrojen gazı üretim verimi açısından değerlendirildiğinde, gaz bileşimindeki hidrojen gazı oranının da, birlikte gazlaştırma sonucunda en yüksek değere ulaştığı gözlemlenmiştir $(\% 71,4)$.

\section{Sonuç}

Farklı oranlarda sorgum içeren Çan linyiti ve sorgum biyokütlesi karışımlarının birlikte gazlaştırılmasında, hem üretilen toplam gaz hacmi hem de hidrojen gazı açısından en etkin biyokütle konsantrasyonu $\% 25$ olarak belirlenmiştir. Karışımdaki biyokütle miktarının artı̧ı1 elde edilen gaz karışımındaki hidrojen gazının oranını arttırmakla birlikte, üretilen toplam gaz hacminde azalmaya neden olmuştur. Sicaklık artışının, birlikte gazlaştırmadan elde edilen toplam gaz hacmi ve hidrojen gazı üretim verimini gazlaştırılmalarından edilen toplam gaz hacimleri ve gazların bileşimleri verilmiş ve bu sonuçlar birlikte gazlaştırma deneyinin sonuçları ile karşılaş̧ırılmışıır. 
Howaniec, N., Smolinski, A., Stanczyk, K., Pichlak, M. 2011. "Steam cogasification of coal and biomass derived chars with synergy effects as an innovative way of hydrogen-rich gas production", Int J Hydrogen Energy, 36(22), 14455-63.

Howaniec, N., Smolinski, A. 2013. "Steam co-gasification of coal and biomasssynergy in reactivity of fuel blends char", Int J Hydrogen energy, 38(36), 16152-60.

Howainec, N., Smolinski, A. 2014. "Effect of fuel blend composition on the efficiency of hydrogen -rich gas production in cogasification of coal and biomass", Fuel, $128,442-450$.

Jeong, H.J., Hwang, I.S., Hwang, J. 2015. "Co-gasification of bituminous coal-pine sawdust blended char with $\mathrm{H} 2 \mathrm{O}$ at temperatures of $750-850{ }^{\circ} \mathrm{C} "$, Fuel, 156, 26-29.

Kumabe, K., Hanaoka, T., Fujimoto, S., Minowa, T., Sakanishi, K. 2007. "Cogasification of woody biomass and coal with air and steam", Fuel, 86 (5-6), 6849.

Lapuerta, M., Hernandez, J.J., Pazo, A., Lopez, J. 2008. "Gasification and cogasification of biomass wastes; effect of the biomass origin and the gasifier operating conditions", Fuel Process Technol, 89, 828-37.

World Energy Council, "World Energy Resources 2016", https://www.worldenergy.org/wpcontent/uploads/2016/10/World-EnergyResources-Full-report-2016.10.03.pdf (Son erişim tarihi: 7 Eylül 2018).
Minchener, J.A. 2005. "Coal gasification for advanced power generation", Fuel, 17, 2222-35.

Moore, T.A., Pearce, S. 2006. "Hydrogen from coal", International Journal of Coal Geology 2006, 65 (3-4), 171-2.

Pinto, F., Franco, C., Andre', R.N., Tavares, C., Dias, M., Gulyurtlu, I., et al. 2003. "Effect of experimental conditions on $\mathrm{CO}$ gasification of coal, biomass and plastics wastes with air/steam mixtures in a fluidized bed system", Fuel, 82, 1967-76.

Rizkiana, J., Guan, G., Widayatno, W.B., Hao, X., Huang, W., Tsutsumi, A., Abudula, A. 2014. "Effect of biomass type on the performance of cogasification of low rank coal with biomass at relatively low temperatures", Fuel, 134, 414-9.

Seçer, A., Küçet, N., Fakı, E., Hasanoğlu, A. 2018. "Comparison of co-gaisification efficiencies of coal, lignocellulosic biomass and biomass hydrolysate for high yield hydrogen production", Int J Hydrogen energy, 43, 21269-78.

Stiege,1 G.J., Ramezan, M. 2006. "Hydrogen from coal Gasification:An economical pathway to a sustainable future", International journal of coal geology, 65 (3-4), 173-90.

Şengüler, ̇. "Ülkemiz Enerji Bütünlemesinde Marmara Ve Trakya Bölgesi Kömürlerinin Yeri”, http://www.emo.org.tr/ekler/c1690de2b615 cc3_ek.pdf. (Son erişim tarihi 30.05.2019)

Velez, F.J., Chejne, F., Valdes, C.F., Emery, E.J., Londono, C.A. 2009. "Cogasification of Colombian coal and 
biomass in fluidized bed: An experimental study", Fuel, 88(3), 424-430.

Veraa, M.J., Bell, A.T. 1978. "Effect of alkali metal catalysts on gasification of coal char", Fuel, 57 (4), 194-200. 